\title{
Alterations of intestinal fora and the effects of probiotics in children with recurrent respiratory tract infection
}

\author{
Ying Zhu ${ }^{1}$, Weizhuo Wang ${ }^{2}$, and Min $\operatorname{Han}^{3}$ \\ ${ }^{1}$ Affiliated Hospital of Heze Medical College \\ ${ }^{2}$ Heze Medical College, Shandong Province, China \\ ${ }^{3}$ Affiliated Hospital of Heze Medical College, Shandong Province, China
}

February 17, 2022

\begin{abstract}
Recurrent respiratory tract infection(RRTI) are one of the major health problems in children. Different degrees of immune deficiency or immaturity, as well as specific or non-specific immune dysfunction are the main causes of RRTI in children with RRTI. Immunomodulators are the most commonly used treatment. Probiotics are viable bacteria that colonize the intestine and affect the host intestinal microbial balance. Probiotics can participate in local and systemic immune regulation in a variety of ways. The aim of this review was to assess the specific impact of probiotics use on recurrent respiratory tract infection in children, the ability of live bacteria to alter intestinal microbial populations and to exert subsequent benefits for the host.
\end{abstract}

\section{Hosted file}

Main Document.doc available at https://authorea.com/users/461112/articles/556877-alterationsof-intestinal-fora-and-the-effects-of-probiotics-in-children-with-recurrent-respiratorytract-infection 